\title{
Decolonising medical causality in the COVID-19 pandemic
}

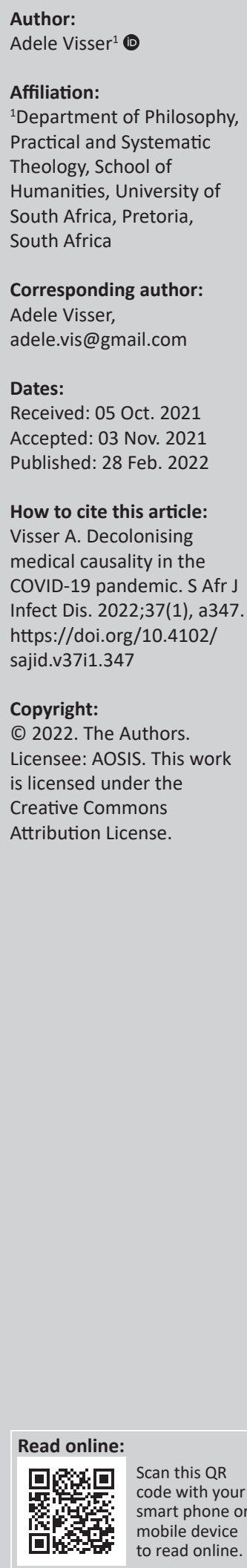

\begin{abstract}
The coronavirus disease 2019 (COVID-19) pandemic has irrevocably changed every aspect of social, medical and economic life globally. Although our traditional Western consideration of the underlying causes have led to massive strides in prevention and control of spread, a wider more inclusive approach, including principles of African and non-Western causality may facilitate our ability to prevent future outbreaks. Decolonising our traditional thoughts on medical causality may compliment the practice of medicine and enrich our understanding of health.
\end{abstract}

Keywords: COVID-19; causality; communitarianism; African philosophy; decolonisation.

The global pandemic caused by severe acute respiratory syndrome coronavirus 2 (SARS-CoV-2) is likely the most significant challenge to face our generation. Understanding this crisis may counter-intuitively be more productive if we apply the Eisenhower principle, whereby a problem is approached not by breaking it into small parts, but rather to make it bigger. ${ }^{1}$ Modern medical pathogenesis is heavily influenced by Humean principles where the constant conjunction between putative cause and putative effect, together with necessary connection, uniformity and universality suggests causality. ${ }^{2,3}$ Using this paradigm, we can simply state that the coronavirus disease 2019 (COVID-19) pandemic is caused by the spread of a respiratory virus, leading to an initial viral response, followed by an inflammatory second phase. ${ }^{4}$ Therefore, in order to regain control over this outbreak, we need restricted spread through social distancing, mask wearing, prevention by vaccination and cure by effective treatment.

Troxell and Snyder ${ }^{5}$ published a case study in causality using the example of a house fire caused by a youth who played with matches. According to fire fighters, the cause of the fire was the matches. However, a physicist may state that this was not sufficient and the presence of ample combustible material was the cause. A psychologist may query this analysis by stating the mental well-being of the child as cause whereas an anti-smoking activist may lay blame on the free availability of matches to those too young for judicious use. Of course, this analysis can go on ad infinitum. The important point is to show that none of these causalities are right or wrong, or even more or less right, but rather that they are complementary.

Using principles of African philosophy may facilitate the process of true root-cause analysis of our current pandemic. African metaphysics do not subscribe to the dualist nature of Western models. There is no distinction between God, the ancestors, people and nature and all these parts of a universal whole is used in the ontological explanation of events such as illness or disaster. There is acknowledgement of certain aspects within this universal complexity to be beyond our perceptual capabilities. ${ }^{6}$ In African culture, illness is also more broadly defined as a state of not being able to function normally, not simply the absence of health. It therefore considers not only physical, psychological and social factors but even environmental and moral cause. ${ }^{7}$ The ethic of care and ethic of nature-relatedness emphasises the importance of responsibility of humans in the upkeep of the environment. ${ }^{8}$

If we critically consider these principles in the assessment of causality in the COVID-19 pandemic, the importance of underlying chronic diseases and comorbidities carry far more weight and social support and communitarianism. In addition, the infringement in harmony between humans and their environment becomes central in the management of the crisis. The unnatural and stressful environment of wet markets, contravene fundamental principles of African harmony. 
Both Western and African causality should be used in complementary fashion in our evaluation of the current crisis facing the world, to enable a comprehensive and lasting attempt to prevention.

\section{Acknowledgements}

\section{Competing interests}

The author declares that she has no financial or personal relationships that may have inappropriately influenced her in writing this correspondence.

\section{Author's contributions}

The author declares that she is the sole author of this correspondence.

\section{Ethical considerations}

This correspondence followed all ethical standards for research without direct contact with human or animal subjects.

\section{Funding information}

The authors received no financial support for the research, authorship and/or publication of this correspondence.

\section{Data availability}

Data sharing is not applicable to this correspondence.

\section{Disclaimer}

The views and opinions expressed in this correspondence are those of the author and do not necessarily reflect the official policy or position of any affiliated agency of the author.

\section{References}

1. Elter J. Make the problem bigger. [cited 2021 Jul 28]. Available from: https:// sustainablesystems.com/make-problem-bigger/

2. Akpan CO. A comparative analysis of causality in Buddhism and African philosophy Educ Res. 2011;2(1):721-729.

3. Williamson J. Establishing causal claims in medicine. Int Stud Philos Sci. 2019;32(1):33-61. https://doi.org/10.1080/02698595.2019.1630927

4. Cevik M, Kuppalli K, Kindrachuk J, Peiris M. Virology, transmission, and pathogenesis of SARS-CoV-2. BMJ. 2020;371:m3862. https://doi.org/10.1136/ bmj.m3862

5. Troxell EA, Snyder WS. Making sense of things: An invitation to philosophy. New York, NY: St. Martin's Press; 1976.

6. Teffo LJ, Roux PJ. Metaphysical thinking in Africa: Themes in African metaphysics. In: Coetzee PH, Roux APJ, editors. Philosophy from Africa: A text with readings. New York, USA: Oxford University Press, 2002; p. 161-156.

7. Sogolo GS. The concept of cause in African thought. In: Coetzee PH, Roux APJ editors. Philosophy from Africa: A text with readings. London, UK: Routledge, 1998; p. 192-199.

8. Ogar JN, Bassey SA. African environmental ethics. RAIS J Soc Sci. 2019;3(1):71-81. 